\title{
Assessing Injury Severity During General War Will the Military Triage System Meet Future Needs?
}

\author{
Lt Col J M Ryan* \\ FRCS, RAMC, Senior Lecturer in Surgery \\ Major J Sibson \\ MB, ChB, RAMC, Registrar in Surgery
}

\section{Squadron Leader Graham Howell \\ FRCS, RAF, Senior Registrar in Surgery \\ The Surgical Unit, Princess Alexandra Hospital, Royal Air Force Wroughton, near Swindon, Wilts and the Department of Military Surgery, Royal Army Medical College, Millbank, London}

"All delays in war are dangerous . . ."

Tyrannic Love - John Dryden 1631-1700

"Will we never learn?"

Sir Heneage Ogilvie 1951

"The flower of our youth dies on the highways and in the taverns of America. . . ."

C T Thompson 1986

SUMMARY: The injuries likely to occur during a future general war will differ in severity and number from those experienced during recent short campaigns, terrorist incidents and natural disasters. If general war should break out in Europe, casualty numbers will lean towards the First World War rather than the Second in scale. Medical assets can expect, at least temporarily, to be overwhelmed with casualties.

To deal with this problem, casualty management will be staged through five echelons or lines of medical support. The्ष principal problem that will face medical attendants at the forward lines will be the sorting of casualties by priority so that those unable to tolerate delay in treatment will be evacuated rapidly before the less severely injured. Sorting will be achieved by the application of a crude scoring system known as Military Triage. We examine this concept and discuss its likely effectiveness in a scenario characterised by limited medical resources and a high flow of casualties.

With the widespread introduction of modern and complex injury severity scoring systems into civilian trauma practice it is timely to examine their potential role in augmenting or replacing the current Military Triage system.

\section{Introduction}

Military medical planners have long realised the need for a rapidly applicable and accurate method of sorting casualties into priority groups for evacuation and treatment following war injury ${ }^{1,2}$. Any method should allow for immediate diagnosis of injury and its severity so that appropriate management decisions can be made. The method currently used by Defence Medical Services in the United Kingdom is called Triage, a term derived from the French Triager, meaning to sort. Its value in war has been repeatedly proven, most recently during the Falklands $\mathrm{War}^{3,4}$. The military triage system was particularly designed to identify, in any group of battle casualties, a small but well defined group whose severity of injury will result in early death if resuscitation and surgery is delayed for any reason. It should also identify other important groups; casualties whose severity of injury dictates a need for early surgery and possible resuscitation, a group who require delayed surgery and a group who are untreatable and beyond medical aid.

With slight adjustment the system may be adapted to a mass casualty scenario in which available medical resources are temporarily overwhelmed. The military triage methodology, tailored to need, has long been integrated into civilian disaster plans and has had its most recent application following the airbus disaster on the M1 motorway near Kegworth, railway disasters at Clapham and Purley and football ground disasters at Bradford and Hillsborough. Current trends in civil practice, both here and in the United States, have been towards an elaboration of the simple and rapid military approach.

Requirements of an Ideal Scoring System for War Use

An effective scoring system for civil use must meet certain basic requirements and these have been listed by Champion 5 . An ideal scoring system for war should meet these needs and adapt or adjust them to the battlefield. The requirements for war include:

Correlation with need. The method of scoring should identify casualties requiring immediate resuscitation and surgery.

Correlation with outcome. It should correlate with outcome (survival or death) if it is to make optimal use of of limited medical assets.

Credibility, Reliability and Practicability. The user must have faith in the system and should see it as a valid 
and reliable method of grouping casualties. It must be adaptable to changing battlefield conditions.

Validity over Time. The system must remain effective over time as casualties pass through echelons of care and are reassessed. In this way it will reflect the effectiveness of resuscitative methods and will draw attention to casualties whose priorities have changed.

Retrospective Evaluation. It should be possible to check, at a later stage, the effectiveness of the system and to evaluate care statistically. This would allow modifications to be made if deficient care was found in certain situations.

Minimum Use of Equipment. An effective system should not require any special equipment and should not impose complex documentation demands on raters.

Before proceeding to examine Military Triage in the light of the above requirements the possible conditions under which the system will be expected to function may be usefully outlined. Despite the existence of excellent records of previous campaigns, the conditions that may prevail on a future battlefield during general war cannot be estimated with certainty. The conditions of a major war, for example in North West Europe, are likely to be more testing than many of the short campaigns of which currently serving military surgeons have had experience $^{6}$. The military writer, C J Dick, gives a particularly clear account of the Soviet vision of the next European battlefield ${ }^{7}$. The Soviets envisage a chaotic and confused battlefield with distinctions between front and rear areas blurred and with fighting taking place throughout the theatre of war. Enemy action will oblige medical assets to move constantly and these will need to be light and mobile. Casualty loads may be expected to be high. Matters will be exacerbated by inexperience among the medical and nursing teams who will have to work for long periods in less than ideal surroundings ${ }^{8}$. The prospect in store for these youthful and inexperienced teams is illustrated by von Clausewitz who has described the elements which make up modern war as danger, exertion, uncertainty and chance ${ }^{9}$. To these elements may be added inexperience, fear, fatigue, hunger, thirst, sleep deprivation and exposure to the elements. Collectively these may well introduce errors and omissions into decision making and to treatment. Whelan ${ }^{10}$ has left a vivid account of these stresses as they affected medical teams working on the Anzio beachhead in 1944.

\section{Military Triage Methodology for General War}

Modern military triage developed from a system devised by French military surgeons during the First World War. Faced with casualties on an unprecedented scale and with limited resources (pre antibiotic era, limited blood) they devised a system of dividing casualties into three groups, one with minor injuries, a group with major injury but with a good outlook if treated, and finally, a grave outlook group who were given the lowest priority for evacuation and treatment.
The current United Kingdom military triage systerri retains the French concept but has refined and tailored ir to modern needs. Military planners recognise the neec for two systems, conventional triage for use wher medical resources are coping with casualty inflow an mass casualty triage when resources are over ? whelmed. These will be discussed separately.

\section{Conventional Triage}

This is the classification by priority of casualtie following wounding and takes place at each line of echelon of medical care. Five lines of care are defined: $\stackrel{0}{2}$

First Line - Integral to fighting units and provided by regimental doctor and his staff.

Second Line - Integral to a field force or division and centred on a field ambulance.

Third Line - Integral to a Corps and centred arounctif surgical facilities. These provide resuscitation and initia

Fourth Line - A theatre of war and centred on genera岕 hospitals. These provide definitive surgery an postoperative care.

Fifth Line - The United Kingdom home base and i\$ centred on static general hospitals and provideg specialised care and rehabilitation.

At first line, the Regimental or Battle Group Post, a medical officer will divide patients into 4 grou a self help group, a minimal (local) treatment grợ (who may include psychiatric casualties), a groxp requiring resuscitation, surgery or both, and a gr\&ipo consisting of the dead and those whose deatho is imminent and unpreventable. The third group, the 5 S requiring surgery, are the group of immediate concen to the Regimental doctor. Here, following battlefiel $\bar{\Phi}$ life support measures, triage is applied to determin $\mathscr{\sigma}_{0}$ evacuation priorities. Conventionally, three groups ar@ defined:

P.1 Those requiring resuscitation and urgent surgery

P.2 Those requiring early surgery and possible resuscitation

P.3 Those requiring delayed surgery.

At the most forward levels of care, triage represents method of visually scoring patients, based on observe injuries during a rapid and superficial examinationo Scoring is by application of integers (P1, 2 or 3 ) to the casualty which decide his priority for evacuation. $\mathrm{O}$ ? arrival at second echelon, the Dressing Station of a Fiel: Ambulance, life support measures are continued an $\oint$ reinforced, and triage, again based on priority fo evacuation, is reapplied. It is evident that the process io dynamic, requiring repeated application to account foD the changing clinical state of many casualties. It is․․․ however, a simple approach based on observation Delay is a key consideration; the rater must be aware of evacuation times between echelons and adjust prioritie accordingly. 
On the arrival of casualties at a field surgical centre (from forward echelons or resulting from local fighting) the triage process continues but is now based on priority for resuscitation and urgent life saving surgery. Postoperative and other casualties are subjected to further triage to decide their priority for evacuation to surgical facilities in the rear, with the element of delay again influencing the decision making process.

The conventional system will not cope with mass casualties which make special demands. Separate systems exist for this eventuality.

\section{Mass Casualty Triage and the P1 Hold Category}

A NATO Glossary [AA P 6(2)] defines a military mass casualty situation as one in which an overwhelming number of seriously injured or otherwise incapacitated individuals, within a limited area or multiple areas and over a brief period of time, are placed upon locally available medical facilities quite unable to supply normal medical care for them ${ }^{1}$. Here, conventional triage must be abandoned with the aim of providing useful medical care to the largest number. To achieve this 4 treatment groups will exist into which casualties may be scored and sorted'. Where a single medical facility is temporarily overwhelmed a situation short of a mass casualty state may exist. Here some of the more complex P1 cases may be placed into a group designated Pl Hold. Surgery is anticipated for these patients following normalisation of conditions.

This section has summarised the intended approach to casualty sorting should general war break out. The following section will examine current techniques designed to enhance decision making and management for large casualty numbers in the civilian setting; a later section will discuss their potential for use on the battlefield.

\section{Civilian Injury Severity Scoring Systems}

Trauma results in about 165,000 deaths annually in the United States. This represents more than twice the total number of deaths in Vietnam. In the United Kingdom, more than 18,000 people die each year as a result of accidents. Despite this, trauma remains the neglected stepchild of North American and British medicine. There is growing concern in the United Kingdom that treatment for the victims of major trauma is unpredictable and often inadequate ${ }^{11}$. There is an increasingly held view that the normal approach to medical management fails in the trauma setting (a view long held by military medical planners). Rutherford ${ }^{12}$ has summarised the problem of trauma most elegantly. $\mathrm{He}$ states "Accident and emergency medicine is differentiated on the basis of a particular time and a particular place. The time is the phase of urgency or crisis, and the place is the reception area of a hospital. It is the interplay of the time and the place which gives accident and emergency medicine its special characteristics."
The realisation that trauma is a unique morbid condition has led to the evolution of new and more effective approaches to diagnosis and decision making. Common to each approach is the characterisation and quantifying of injury severity by applying a numerical score deduced from considering the following, either alone or in combination: the degree of physical (anatomical) injury, measured physiological variables, age and pre-morbid conditions. The history and mechanism of injury is also considered by most approaches. The most widely used systems are outlined below.

\section{Anatomical Systems}

Anatomical scores or scales are methods for describing patient injury which quantify, weigh and mathematically combine clinical details. They provide a once only characterisation of the extent of injury and are unable to reflect changing physiological parameters. Accuracy demands definitive clinical diagnosis; in general these systems are therefore best suited to the hospital setting where full investigation may precede diagnosis and management.

\section{The Abbreviated Injury Scale (AIS)}

In 1969 the Committee on Medical Aspects of Automotive Safety sponsored the development of $\underset{\mathbb{D}}{\mathbb{D}} \mathbb{D}$ rating system for injury incurred in automobile्ల accidents ${ }^{13}$. They were concerned only with the implications of blunt injuries received in road traffi accidents. The rating system developed was designated the Abbreviated Injury Scale (AIS) and was designed te assess injury on a scalar basis in each of five bode systems. The designated body systems were: generaᄅ़ head and neck, chest, abdominal region and extremities. The method of scoring is simple:

\section{AIS 0 No injury}

AIS 1 Minor injury

AIS 2 Moderate injury

AIS 3 Serious/Severe but not life threatening

AIS 4 Serious/Severe and life threatening

AIS 5 Critical injury; survival uncertain

AIS 6 Fatal or death imminent (non-survivable).

The original system contained a subjectively compiled dictionary describing over 1,200 injuries. Complete tables outlining the system and method of scoring may be found in the Committee's original papers ${ }^{13,14}$.

The system has undergone numerous modifications over the years, the dictionary has been widened and improved and the latest, AIS 85, now includes a method for scoring penetrating trauma ${ }^{14}$. Although AIS has been found to be consistent and can be related to mortality for blunt trauma following RTAs with an accuracy approaching $100 \%$, it has many weaknesses: $\widetilde{N}$

i. It is a static once and for all system that does not $\tilde{N}^{N}$ account for changing physiology. 
ii. Definitive diagnosis is required if scoring is to be accurate. It is therefore not suited to field use.

iii. The latest system, AIS 85, has not been long enough in use to determine its accuracy for penetrating injury. It has never been correlated for ballistic injury.

iv. It utilises the highest single AIS scores rather than overall.

$\mathrm{v}$. It is inadequate in describing multiple injuries.

vi. AIS lacks internal and mathematical consistency. A 3 grade for a particular injury may not carry the same risk of death as a similar score for another. Additionally, the increase in severity from 1 to 2 is much less than the increase in severity when the score changed from 4 to 5 . vii. Interrater reliability is generally believed to be poor.

\section{The Injury Severity Score (ISS)}

In an attempt to rectify some of these weaknesses, Baker et al in 1974 developed the Injury Severity Score (ISS). ISS, in essence, is an adjusted and modified form of the AIS ${ }^{15.16}$. It takes the AIS scores for the three most severely injured regions, the numbers are squared and then added. A little immediate confusion is caused by Baker and her colleagues as they describe regions differently to the AIS scheme and they add a sixth. The ISS regions are listed below.
1. Head or neck
2. Face
3. Chest
4. Abdominal or pelvic contents
5. Extremities or pelvic girdle
6. External

A further departure from AIS methodology is the adoption of 5 as the maximum score in any region, the maximum ISS score is therefore $75\left(5^{2}+5^{2}+5^{2}\right)$. An AIS score of 6 in any body region incurs the maximum score of 75 irrespective of any other injury. This is a logical step as a score of 6 indicates death or its imminence. The method is therefore capable of expressing the cumulative effect of injury to several body cavities. Its use of a quadratic expression based on the sum of the squares of the three most severely injured body regions has been shown to have greater mathematical validity than AIS scores.

ISS correlates better with mortality than AIS and has become the standard by which anatomical scoring systems are measured. Experience in the United States has shown statistically that an ISS of 16 is predictive of $10 \%$ risk of death following blunt trauma.

Patients with an ISS of $<25$ rarely die. Above 25 the probability of death increases sharply. Thus, trauma patients with scores between 15 and 25 represent a group of patients ideally suited to retrospective evaluation. Their fate should give a measure of the quality of care given and appropriateness of triage. Baker and her colleagues point out that although high scores $(>25)$ are associated with a high mortality, patients with scores of
$>50$ may survive with optimal care. An importan finding with ISS is the role of age in severe injury. Ags $>55$ has been shown to render a given injury more severe. Reliability for penetrating injury remaing uncertain; a dictionary describing penetrating injury 8 in current use but time is needed to test its validity? Potential use in predicting the severity of penetratin $\overrightarrow{F^{\circ}}$ war injury will be discussed in a later section of this paper.

In summary, ISS provides an accurate numeric description of the overall severity of injury in patien with multiple injury and scores correlate well wiff survival. However, serious weaknesses exist.

i. The system fails to discriminate multiple injuries in. $\vec{a}$ single region. For example, if a casualty has tw abdominal injuries graded 2 and 3 , only the 3 grade mig be utilised.

ii. Equal values of the ISS may have significant different mortality rates.

iii. In field use the system is too subjective and therefor liable to inaccuracies.

iv. It would seem to be a poor indicator of injury severity with penetrating ballistic injury as this is characteriset by clustering of injury in one region.

v. Interrater reliability has been questioned, particularty when used for penetrating injury. This may impot with experience.

A review of current experience with anatong scoring systems in the peacetime setting suggests are not ideal for military use; they are static once andffeळ all systems and lack the dynamism necessary ingho battlefield environment, they are too subjective whem not backed up by accurate investigative techniques of unproven value in penetrating injury and interrater difficulties remain. Furthermore, they lack a physiological basis. Their best use is in the hospital setting an in this environment they become very useful retro. spective instruments.

\section{Physiological Systems}

Physiological injury severity scoring systems are based on the assumption that measurable physiologic changes take place after trauma. Pulse rate, systo blood pressure, respiratory rate and depth, and neurological status can be rapidly and accuratesy recorded with the minimum of equipment. Application of scores based on physiological parameters has bee्g under development for more than 20 years. Theşe methods introduce two features which, on the surface 9 least, render them more suitable to the military environment; these are objectivity and dynamism. They should be more accurate in assessing the immediate response to trauma than anatomical scores, with the proviso that, if applied too soon after trauma, the young patient may exhibit temporary homoeostasis even in the presence of severe injury. False negative resu should be minimised by repeatedly applying the scores, 
particularly where the history suggests severe injury. The most important of these scales are discussed below.

\section{The Trauma Index -1971}

A scheme devised by Kirkpatrick and Youmans in $1971^{17}$, it represented the first attempt to assess injury severity objectively by measuring physiological parameters.

\section{The Glasgow Coma Scale (GCS) - 1974}

Teasdale and Jennett ${ }^{18}$ introduced this scoring system in an attempt to accurately measure the neurological status of patients following head injury; the method of scoring is based on best response and is outlined at Table 1. The lower the score the greater the likelihood of significant neurological deficit. The method has been shown to correlate with mortality and the Glasgow Outcome Scale ${ }^{19}$.

The Triage Index -1980

Introduced by Champion and his colleagues ${ }^{20}$ as a field Triage instrument measured 16 physiological variables shown to be related to probabilty of survival or death. It has been superceded by the Trauma Score.
The Trauma Score (TS) - 1981

This system applies coded values to variable physio- $\frac{3}{8}$ logical parameters and adds them ${ }^{21}$. It is a field system $\stackrel{\varnothing}{\varrho}$ measuring 4 parameters and combined with the Glasgow Coma Scale. The score range is 1 to 16 , the higher the score, the better the outlook for survival. The? methodology is given at Table 2 . Probability of survival $\overrightarrow{\vec{s}}$ scores for each TS value have been calculated (Table 3 ). $\overrightarrow{0}$ Champion states that the method is a good field triage $\frac{}{\sigma}$ instrument but accepts that it is somewhat elaborate and $\overline{\bar{c}}$. cumbersome. Wide usage has shown a high degree of $\vec{\nabla}$ accuracy in measuring severity of injury and scores correlate well with outcome $e^{22,23}$. A TS of 13 has been shown to correlate with a mortality of $10 \%$ (equivalent $\overrightarrow{0}$ to an ISS score of 16). Strengths include objectivity, $\vec{\overrightarrow{ }}$ dynamism and its use as a measure of the effect of early $\vec{\sigma}_{\mathscr{\sigma}}$ treatment when repeated at intervals, Champion and $\mathrm{Sacco}^{24}$ have suggested a cross relationship with

Table 2

Trauma Score Methodology

\begin{tabular}{l}
\hline A Respiratory Rate \\
$10-24$ \\
$25-35$ \\
$>35$ \\
$<10$ \\
0
\end{tabular}

Table 1

The Glasgow Coma Scale

\section{Eyes Open}

Spontaneously

To Voice

To Pain

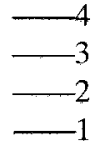

2. Best Verbal Response

Orientated

Confused

Inappropriate Words

Incomprehensible Sounds

No Response

\section{Best Motor Response}

Obeys Commands

Localises Pain

Flexion Withdrawal (Pain)

Decerebrate Flexion (Pain)

Decerebrate Extension (Pain)

No Response

-6
-5
-4
-3
-2
-1

Score is the sum of the three section $(1+2+3)$

\section{B Respiratory Effort \\ Normal \\ Retractive/None}

\section{Systolic Blood Pressure}

$>90$

$70-90$

$50-69$

$<50$

0

\section{Capillary Refill}

2 seconds

$>2$ seconds

None

\section{E Glasgow Coma Scale (see Table 1)}

14-15

11-13

8-10

$5-7$

3-4

Trauma Score computed by adding scores for sections $A$ 서 B, C, D \& E. 
Table 3

The Probability of Survival (PS) for individual trauma scores

\begin{tabular}{cc}
\hline Trauma Score & $\mathbf{P \%}$ \\
\hline 16 & 99 \\
15 & 98 \\
14 & 96 \\
13 & 94 \\
12 & 89 \\
11 & 82 \\
10 & 72 \\
9 & 59 \\
8 & 45 \\
7 & 31 \\
6 & 21 \\
5 & 13 \\
4 & 7.5 \\
3 & 4.3 \\
2 & 2.5 \\
1 & 1.4 \\
\hline
\end{tabular}

conventional mass casualty grading (Table 4 ). Interrater reliability has been shown to be $>95 \%$ in field tests conducted by Moreau et $\mathrm{al}^{25}$. Field use does not impose additional tasks above those normally carried out on trauma victims. A further claim made by Champion's team is that TS is a useful instrument for patient assessment and for teaching triage skills.

In its present form the system has serious failings, particularly when considered from a battlefield point of view:

i. Boyd $^{22}$ regards its sensitivity rate as only $80 \%$. That is to say, it will fail to identify $20 \%$ of those severely injured. One of the reasons for this is the maintenance of physiological homoeostasis in young and fit subjects for a period following serious injury. This pitfall may be overcome by recognising this feature and by repeating the scoring.

ii. The system does not recognise the existence of preinjury morbid conditions which may affect the variables. iii. Extremes of age affect scoring.

iv. Although the method has been applied to penetrating trauma ${ }^{26}$ its sensitivity would appear to be still too low for its use as a battlefield triage instrument.

Champion states that TS, used alone as a field triage instrument, would result in false optimism and pessimism in a significant number of cases; a disastrous prospect on a battlefield. He suggests that TS accuracy would be improved if an anatomical element was added and note taken of the mechanism of injury. This approach will be discussed later.
The CRAMS Scale and Prehospital Index-1982 \& $198 \%$

Developed between 1982 and 1986 as field triage् instruments for use by staff working in the prehospita or field environment (paramedics) ${ }^{27,28}$; these attempt $t \Omega$ measure the physiological reponse to trauma in a rapid way which requires minimum equipment and experience. The scores are used to determine the leve of sophistication required for optimal management and thus lack applicability to the battlefield.

\section{Combination Schemes}

With the realisation that no one system would meed the requirements for an ideal scoring system the possibility of combining physiological and anatomic $\vec{\Phi}$ systems has been considered by various groups. A number of these are now in clinical use.

\section{TRISS Methodology - 1981}

Following a retrospective analysis of the performanc? of TS alone and in combination with ISS and patient agect the TRISS methodology emerged. The system utilise $\$$ weighted values of the TS, ISS and patient age. The weightings have been derived from regression analysis applied to data from over 25,000 patients under study bo the ongoing Major Trauma Outcome Study (MTOS) The MTOS data base has been used to compute 'LD50' for the group. Outcome for new patients carge contrasted with data base information, thus givin measure of the quality of care delivered to individual. A probability of survival (PS) can to estimated with a high degree of certainty for any traugiflo victim and therefore attention will be drawn to paticist who should not have died. This instrument has no foid application and will not be discussed further. A $\overrightarrow{\text { fut }}$ account of the methodology may be found in a numbe of recent papers ${ }^{5.11 .22}$.

\section{The American College of Surgeons Triage Decision Scheme-1986}

The College Committee on Trauma has devised decision making scheme which incorporates static and dynamic indicators but also gives significance to the mechanism of injury, medical history and to th: experience of the rater. It is a flow chart, the fina

Table 4

A suggested cross relationship between mass casualty priority groupings and trauma scores

\begin{tabular}{l} 
Priority \\
\hline T1 (UK) 1st (USA) \\
T2 (UK) 2nd (USA) \\
T3 (UK) 3rd (USA) \\
T4 (UK) 4th (USA)
\end{tabular}

Trauma Score

4-10

11,12

15,16

$<3$ 
decision being whether to admit to a designated trauma centre or to an ordinary hospital. As such it lacks battlefield relevance (there are no varying levels of trauma care available in field hospitals). The scheme is discussed in a recent bulletin of the American College of Surgeons ${ }^{29}$.

\section{The Revised Trauma Score - 1988.}

The system evolved following an analysis of TRISS failures, it utilises GCS, Systolic BP and Respiratory Rate. Coded values are assigned to specific ranges of each parameter. The MTOS data base is used to determine weights for each variable. The methodology can be studied in detail by reference to Boyd et $\mathrm{al}^{22}$. Like TRISS its best use is as a measure of quality of delivered care. Champion, however, suggests that the RTS should be ideal as a simplified triage tool. It is too early to comment on this potential use of the system.

\section{Assessment of Injury Severity Score Using the Wound Data and Munitions Effectiveness Team (WDMET) Study Data}

Bellamy, from the United States Army Medical Corps, has applied the ISS system to data compiled during the Vietnam $\mathrm{War}^{23}$. He states that little attention has been paid to differences in rating between blunt and penetrating injury and, in particular, penetrating war injury. Using the data collected by WDMET, he studied the applicability of the ISS system to the war setting and discovered that a different ISS/Mortality relationship existed for injury caused by war munitions. ISS underscored the severity of injury to a very significant extent, a finding for ballistic injury reported earlier by Beverland and Rutherford in Belfast ${ }^{30}$. Bellamy feels that the ISS system and AIS 85 (the latest AIS modification) are unsafe for military use in their present format. He also noted that interrater agreement was poor for military wounds. The possible reasons for the ISS and AIS systems failure are of interest. First, ISS does not recognise multiple injury in a single cavity, yet torso missile wounds are known to result in clustering of injury in body regions. WDMET data has revealed that case fatality rates rise $15 \%$ with each additional viscus injured in penetrating abdominal injury. Feltis, in a review of Vietnam casualties, has conclusively shown that mortality is directly related to the number of organs injured in the abdomen ${ }^{31}$. With four or more organs involved the mortality was $>80 \%$. Current anatomical scoring techniques ignore these key aspects of penetrating war injury. Second, Bellamy and Rutherford feel that the lethal effects of penetrating ballistic injury in war are not fully appreciated and point out that the lethality of ballistic injury is significantly greater than injury received in RTAs. Finally, battlefield conditions impose difficulties with access, evacuation and treatment of casualties and this may increase the lethality of wounds. This is unlikely as an increased lethality with ballistic wounds has also been observed in the ideal clinical setting of Belfast where evacuation 3 times were short and first class management available.

Bellamy has detailed modifications to the ISS system $\bigcirc$ that may allow for the foregoing. He suggests adding $1 \frac{7}{7}$ to the AIS 85 value assigned to the most severely injured organ as long as the AIS 85 value of an additional organ $\overrightarrow{\vec{F}}$ injury is 2 or greater but less than 5 . Comparisons using this modification improved WDMET and ISS correction but underscoring probably persists.

This study is not encouraging for military medical $\frac{\bar{D}}{\vec{D}}$ planners but it underwrites the view that anatomical $\varrho$ scoring methods are unsuitable instruments for incorporation into field triage.

\section{The United Kingdom Military Triage System - Possible Modifications}

An ideal military triage system should rapidly and accurately identify the severely injured in danger of $\frac{\vec{\omega}}{\omega}$ imminent death and should determine the level, pace and intensity of initial management. It should also오 indicate those casualties whose severity of injury is such that treatment will be ineffective and a drain on limited resources, severe head injuries for example. It should leave a record or form a data base to examine its effectiveness retrospectively.

There is much subjective evidence that the curref military triage system meets at least some of these nee $\mathbb{R}$ but there is no objective evidence and no data base available from past campaigns. Such evidence as exis 8 from civilian experience of new scoring metho suggests that none could safely replace the currem decision making system but they might usefully augme the military system. Current civilian scales are affected by age, pre-injury morbidity, pregnancy and concurrent $\stackrel{0}{0}$ medication. Such considerations should not influence $\stackrel{\square}{\perp}$ battlefield scoring for obvious reasons. Possible military/ $\vec{\nexists}$ civilian combinations might include:

\section{Military triage with additional physiological scoring}

There is no evidence to support the replacement of the military triage system by a physiological scoring system. However, it would be useful to apply the TS or RTS in tandem with Triage. TS or RTS should be useful in field hospitals as indicators of reponse to resuscitation and or surgery.

\section{Military triage with additional anatomical scoring}

Bellamy has shown these systems to be unsuitable. Anatomical scores in the hospital setting would provide retrospective information but they have no current place in management decision making for ballistic trauma.

Military triage with additional combination scoring

The only suitable instrument that might augment military triage decision making is the American College $\tilde{N}$ of Surgeons Triage Decision Scheme. However, it is a $\underset{\omega}{ }$

s


complex, time consuming approach and would be unsuitable for use with large numbers of casualties. It is a good template which incorporates a mixed anatomical and physiological approach and takes the medical history and mechanism of injury into account; it merits military consideration.

No suitable United Kingdom war casualty data base exists from which weighted variables could be calculated. The civilian MTOS (USA) and MTOSUK data bases could not be applied to ballistic injury in war. Thus, no prechart could be drawn or 'LD50' calculated. These systems therefore have no current applicability to a future battlefield during general war.

\section{Conclusions}

The chief interest of those engaged in caring for battle casualties is the lowering of mortality and morbidity. This involves rapid access to the casualty, accurate assessment of the severity of injury, institution of immediate treatment and evacuation through lines of medical care so that ultimately he will reach a medical facility for definitive treatment. Of key importance in this cascade of activities is the recognition of a group of casualties who, by virtue of the severity of their injuries, will rapidly succumb shortly after injury. These casualties must be recognised. Equally important is the recognition of injury so severe that outcome will be unaffected by treatment, particularly important for many penetrating head wound casualties.

Military triage is currently relied upon to meet these needs. In a future general war, characterised by chaos and limited resources, it is reasonable to consider whether it will be adequate. It is axiomatic that any scheme suggested to augment or replace it must be of proven validity. The least requirement is that it should be as good as the existing system; and if used in combination it should improve effectiveness.

Of the injury severity scoring systems currently in civilian field use none would appear to be ideally suited to the battlefield and indeed might underestimate the severity and lethality of penetrating ballistic injury ${ }^{23.30}$. However, these systems are being improved and modified and may well ultimately provide the Defence Medical Services with an accurate and easily usable instrument to replace or at least augment the current military triage system. A physiological scoring system could be usefully applied to work in parallel, not only to assist triage decision making, but to provide useful information on patient progress in field hospitals and build a data base for retrospective assessment. An anatomical scoring system would seem to have no place in initial decision making but might prove useful after definitive diagnosis and treatment. Data collected could augment other casualty data for more accurate post war analysis.

Future trends in the development of scoring systems will be observed with interest. Of particular value would be a system that would allow collection of meaningfu⿺廴⿻肀二𠃋 data for evaluating battlefield care so that our casualts treatment regimens may be geared to providing optima care for the wounded soldier.

\section{REFERENCES}

1. Kirby N G and Blackburn G. Field Surgery Pock Book. 1978. London: HMSO.

2. HAYWOOD I R. Triage. J of the Assoc of Immed Care 198 7: 31-35.

3. JACKSON D S, et al. The Falklands War: Army Fiele Surgical Experience. Ann R Coll Surg Engl 1983; 65: 281 285.

4. RYAN J M. The Falklands War - Triage. Ann R Coll Surg Engl 1984; 66: 195-196.

5. Champion H R. Assessing the severity of trauma. In: Westaby S, editor. TRAUMA Pathogenesis ant Treatment. Pp 85-94. 1989. London: Heinemann Medica्क Books.

6. Walker J W. The Connundrum of Air-Land Warfares RUSI 1988; Summer Vol: 15-22.

7. DiCK C J. Soviet operational art, Part 1: The fruits experience. Int Def Rev 1988; 21: 755-761.

8. RYAN J M, et al. Field Surgery on a Future European Battlefield. A review of its provision, problems and controversies 1989. Submitted.

9. Howard $M$ and Paret P. Carl von Clausewitz, 'On WaO 1976. New Jersey: Princeton University.

10. Whelan $T J$, Burkhalter $W$ E and GomezōatT Management of War Wounds. In: Welch C E, edi⿻日禸 Advances in Surgery Vol 3 1968. Chicago: Year Bס्षे Medical Publishers.

11. YATES D W. Injury scoring systems. Int Therapy $1989,10 \div$ 38-44.

12. Rutherford W H, Nelson P A M and Wilson Dश्म? Accident and Emergency Medicine 1980. London: Pit角品 Medical.

13. Committee on Medical Aspects of Automotive Safety Rating the Severity of Tissue Damage. 1 The Abbreviated Injury Scale. JAMA 1971; 215: 277-280.

14. Committee on Injury Scaling. Abbreviated Injury Scale 1985 Revision. Arlington Heights, Il. America $\vec{B}$ Association for Automotive Medicine, 1985.

15. BAKER S P, et al. The Injury Severity Score: A Method fo Describing Patients with Multiple Injuries and Evaluating Emergency Care. J Trauma 1974; 14: 187-196.

16. BAKER S P and O'Neill B. The injury severity score: a update. J Trauma 1976; 16: 882-886.

17. KIRKPATRICK J R and Youmans R L. Trauma Index: a aid in the evaluation of injury victims. I Trauma $1971 ; 1)$ 711-714.

18. Teasdale $G$ and Jennett B. Assessment of coma an impaired consciousness: A practical guide. Lancet 1974; i 81-84.

19. Jennett B, Teasdale $G$ and Braakman R. Predicting outcome in individual patients after severe injury. Lance 1976; i: 1031.

20. CHAMPION H R, et al. Assessment of injury severity: The Triage Index. Crit Care Med 1980; 8: 201-208.

21. Champion H R, et al. The Trauma Score. Crit Care Met. 1981; 9: 672-676.

22. Boyd C R, Tolson M A and Copes W S. Evaluating Trauma Care: The TRISS Method. I Trauma 1987; 2 ' 370-378.

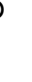


23. Bellamy R F and Vayer J S. Assessment of Penetrating Injury Severity. In: Maull K I, editor-in-chief. Advances in Trauma Volume 3 1988. Pp 163-181. Chicago: Year Book Medical Publishers, Inc.

24. Champion H R and Sacco W J. Trauma Severity Scales. In: Maull K I, editor-in-chief. Advances in Trauma Volume 1 1986. Pp 1-20. Chicago: Year Book Medical Publishers, Inc.

25. Moreau M, et al. Application of the Trauma Score in the Prehospital Setting. Ann Emerg Med 1985; 14: 1049-1054.

26. SACco W J, et al. The Trauma Score as Applied to Penetrating Trauma. Ann Emerg Med 1984; 13: 415-418.

27. GormicAN S P. CRAMS Scale: field triage of trauma victims. Ann Emerg Med 1982; 11: 132-135.

28. Koenler J J, Baer L J and Malafa S A. Prehospital $\$ index: a scoring system for field triage of trauma victims. Ann Emerg Med 1986; 15: 178-182.

29. The Committee on Trauma of the American College of Surgeons. Appendix $F$ to the Hospital Resources ${ }_{0}$ Document: Field categorisation of trauma patients (field triage). Bull Amer Coll Surg 1986; 71: 17-21.

30. BEVERLAND D E and Rutherford W H. An assessment of the validity of the Injury Severity Score when applied to gunshot wounds. Injury 1983; 15: 19-22.

31. Feltis J M. Surgical experience in the combat zone. Am J Surg 1970; 119: 275. 